\title{
Experimentally investigating the influence of mineralogy on the geochemical preservation of microbial fossils during diagenesis
}

\author{
JULIEN ALLEON ${ }^{1}$, JEAN-CHRISTOPHE VIENNET ${ }^{2}$, \\ JOHANNA MARIN-CARBONNE ${ }^{3}$ AND SYLVAIN \\ BERNARD $^{2}$ \\ ${ }^{1}$ University of Lausanne \\ ${ }^{2}$ Institut de Minéralogie, de Physique des Matériaux et de \\ Cosmochimie, Sorbonne Université - CNRS - MNHN \\ ${ }^{3}$ Université de Lausanne \\ Presenting Author: julien.alleon@gmail.com
}

The molecular composition of Archean organic matter may provide crucial insight into early life evolutionary history [1]. Decoding this information yet requires a precise understanding of the molecular transformations that the original organic materials underwent during the geological burial history of their host rocks [1]. An important fossilization parameter is the mineralogy [2]. Following the experimental demonstration that entombment within silica minimizes the molecular degradation of microorganisms during advanced diagenesis [3], we recently experimentally investigated the influence of $\mathrm{Ca}$-carbonates on the degradation of cellulose during a simulated diagenetic history $\left(250^{\circ} \mathrm{C}, 250\right.$ bars, 10 days). FTIR and STXM-XANES data collected on the experimental residues clearly show that the presence of Ca-carbonate significantly intensified the degradation of cellulose, suggesting that the distinctive molecular features of fossil organic biomolecules are likely to be lost faster in carbonate-rich rocks than in silica-rich cherts. Results of similar experiments conducted using samples of the Pleistocene stromatolitic cherts of the Magadi Lake (Kenya), rich in fossil organic biofilms [4], confirm that the organic compounds composing the fossil biofilms, initially closely associated with nanometric Ca-carbonate, experienced more degradation during experiments than those of fossil biofilms initially only associated with silica. Of note, these experimental results confirm the conclusions drawn from the fine-scale characterization of the $1.88 \mathrm{Ga}$ organic microfossils of the Gunflint cherts (Canada) [5]. We discuss here the possible mechanisms responsible for the detrimental effect of carbonates, as well as the implications for the search of biomolecular information in ancient rocks on Earth or on Mars.

[1] Alleon et al. (2021), Communications Earth \& Environment 2, 6.

[2] McMahon et al. (2018), Journal of Geophysical Research: Planets, 123, 1012-1040.

[3] Alleon et al. (2016), Chemical Geology 437, 98-108.

[4] Reinhardt et al. (2019), Biogeosciences, 16, 2443-2465

[5] Alleon et al. (2016). Nature communications 7, 11977. 